\title{
Modeling climate change effects on winter ski tourism in Andorra
}

\author{
Marc Pons-Pons $^{1,2,3, *}$, Peter A. Johnson ${ }^{3}$, Martí Rosas-Casals ${ }^{1,4}$, Bàrbara \\ Sureda $^{1}$, Èric Jover ${ }^{2}$ \\ 1 Sustainability Measurement and Modeling Lab (SUMMLab), Universitat Politècnica de \\ Catalunya (UPC), EET-Campus Terrassa, 08222 Barcelona, Spain \\ 2'Observatori de Sostenibilitat d'Andorra (OBSA), Placa de la Germandat 7, AD600 \\ Sant Julià de Lòria, Principat d'Andorra \\ 3 Department of Geography, McGill University, 805 Sherbrooke Street West Montreal, \\ Quebec, Canada H3A 2K6 \\ ${ }^{4}$ ICREA-Complex Systems Lab, Universitat Pompeu Fabra -PRBB, Dr. Aiguader 88, 08003 \\ Barcelona, Spain
}

\begin{abstract}
Mountain regions have been idefieid as especially vulnerable areas to climate change. Changes in snowfall, glacier retreat and shifts in biodiversity amount and distribution are some examples of the sensitivity of mountain ecosystems. Moreover, in many mountain economies, reliable snow cover plays a key role as an important resource for the winter tourism industry, the main income source and driving force of local development in such regions. This study presents a georeferenced agent-based model to analyze the climate change impacts on the ski industry in Andorra and the effect of snowmaking as future adaptation strategy. The present study is the first attempt to analyze the ski industry in the Pyrenees region and will contribute to a better understanding of the vulnerability of Andorran ski resorts and the suitability of snowmaking as potential adaptation strategy to climate change. This study projects a reduction on the ski season length and the drop of the number of skiers especially in the lowest elevation ski resort of this region. Moreover, this work indicates that snowmaking cannot completely solve the problem of ensuring snow cover at low elevation ski resorts and should be considered as a suitable short-term strategy, but not as a sustainable long-term adaptation strategy. The resulting model can be used as a planning support tool to help local stakeholders understand the vulnerability and potential impacts of climate change and in the decision-making process of designing and developing appropriate sustainable adaptation strategies to future climate variability.
\end{abstract}

KEY WORDS: Climate change impacts, Winter tourism, Snowmaking, Adaptation, Agent-based modeling.

*Corresponding author Email address: marc.pons-pons@.upc.edu 


\section{Introduction}

Mountain regions have been idefneid as especially vulnerable to climate change. The rapid retreat of glaciers, important changes in snowfall amount and frequency and shifts in biodiversity amount and distribution are some examples that demonstrate the sensitivity of mountain ecosystems (Beniston 2003, IPCC 2007). Moreover, in many mountain economies, reliable snow cover plays a key role as an important resource for the winter tourism industry, the main income source and driving force of local development in such regions (Beniston 2003). The winter tourism industry has been ifledtiby gov ernmental and intergovernmental climate assessments as potentially vulnerable to climate change (CADS 2010, IPCC 2007,). In recent years many studies have analyzed the impacts of climate change on the ski industry in regions e.g such as the European Alps (Breiling \& Charamza 1999, Elsasser \& Bürki 2002, König \& Abegg 1997, Steiger 2010, Steiger \& Mayer 2008, Uhlmann et al. 2009,), Canada (Scott et al. 2003, 2006, 2007), USA (Dawson \& Scott 2010, Dawson et al. 2009, Scott et al. 2008), Sweden (Moen \& Fredman 2007), Australia (Galloway 1988, Bicknell \& McManus 2006), Japan (Fukushima et al. 2003), and South Korea (Heo \& Lee 2008). All these studies indicate to a greater or lesser extent that climate change will lead to impacts such as ski season length reductions, loss of skiable areas and drop of visitors both in low altitude and low latitude ski resorts.

Andorra is a small and mountainous country located in the middle of the Pyrenees between France and Spain, with a population of nearly 80,000 inhabitants and an area of $468 \mathrm{~km} 2$. Andorra receives more than 10 million tourist visits every year (Andorra Turisme 2010). Hence winter tourism is presented as one of the main income sources and driving force of local development. Due to this strong reliance of the Andorran economy on winter tourism, it is critical to evaluate the extent of climate change on the ski industry. A central concern is the possibility that skiing would no longer be viable even with adaptation strategies, such as artificial snowmaking. This has become a critical issue not only to assess the sustainability of the ski industry but the sustainability of the current development model of the entire country. In this context, although the Pyrenean region is presented as one of the most important ski areas in Europe after the Alps, covering the north of Spain, the south of France and Andorra, the vulnerability of this ski industry still remains unexplored (CADS 2010, Scott et al. 2007, Yang \& Wan 2010). This paper will analyze the potential reduction of the season length in Andorran ski resorts due to climate change, as well as the subsequent drop in number of skiers and their expenditure. The methodology used is based on a georeferenced Agent Based Model (ABM) that takes into account the skiers response and the adaptive effect of snowmaking on future season length. ABM, also known in some disciplines as Multi-Agents Systems (MAS), is dened as a simulation method in which autonomous and heterogeneous agents (i.e., individual people, animals or organizations) share a common environment and interact simultaneously both upon a landscape and among each other led by a self-interest or common interest (Berger \& Schreinemachers 2006, Ligmann-Zielinska \& Jankowski 2007). Spatially referenced ABM appears as a promising approach for 
exploring complex space-time dynamic interactions between coupled human and environmental systems and capturing emergent macro-level phenomena from micro-level individual actions (Bousquet \& LePage 2004, Deadman et al. 2004). In recent years spatially referenced ABM have been used to analyze a broad spectrum of spatial phenomena such as the water and agriculture management (Bithell and Brasington 2009), the dynamics in ancient human and primate societies (Axtell et al. 2002), the land use and land cover change (Deadman et al. 2004, Parker et al. 2003), the spatio-temporal movement of marine mammals and maritime traffic in the St. Lawrence estuary in Quebec, Canada (Parrott et al. 2011), the residential segregation in a city (Crooks 2010) or the spreading of a pine beetle infestation (Perez \& Dragicevic 2010). However, because of the novelty of this technique only few studies have applied a georeferenced ABM to model tourism phenomena. Gimblett \& Skov-Petersen (2008) and Itami et al. (2002) used ABM for the simulation and visualization of visitor patterns of movement in recreational landscapes such as Parks and protected areas. On the other hand, Johnson \& Sieber (2009, 2010, 2011) developed an ABM of tourism dynamics in the Canadian province of Nova Scotia. The model designed as a Planning Support System (PSS) simulates the movement, the destination preferences and the interactions of tourist agents across a geo-referenced landscape of 35 main tourist destinations

Georeferenced ABM can also be seen as a type of Planning Support System (PSS). This approach is well suited for scenario development, data analysis, problem diagnosis and policy comparison (Ligmann-Zielinska \& Jankowski 2007, Johnson \& Sieber 2011). Moreover, the enhancement and the understanding of the interplay between social and ecological systems such as human responses to environmental changes or the impact of their actions upon it can support the decision-making processes by involving cross-disciplinary knowledge (Smajgl et al. 2011).

The main goal of this study is to analyze, by means of a geo-referenced ABM, the potential climate change impacts on Andorran ski industry in terms of ski season length reduction in selected ski resorts and the subsequent drop of skiers and their expenditure in the region. Moreover, the scenarios generated by the model also take into account the effects of artificial snowmaking on enhancing the snow cover and extending the future season length. In this way more realistic scenarios are generated while the suitability and sustainability of this adaptation strategy can be assessed.

The paper is organized as follows: in section 2, we present the structure and the components of the georeferenced ABM. That is the different layers making up the environment, the agents and their features, and the rules and patterns governing the interactions between agents and the environment. Once the model has been described, section 3 presents the specfic scenarios generated in order to assess the future climate impacts on the ski industry and the resulting outcome for each of these different projections. Finally sections 4 and 5 present and discuss the main findings of the paper, the suitability of the methodology used in the study and the further work.

\section{Model description}


One of the main challenges in climate change impacts studies has been to relate the physical impacts and changes in the environment with their human implications such as socioeconomic impacts or human responses. To overcome this difficulty we present a georeferenced ABM that simulates an average winter season and relates the climate change impacts on the snow cover with their socioeconomic implications in the region such as season length, skiers and expenditure reductions in three different scenarios: one present scenario and two future scenarios assuming a $2{ }^{\circ} \mathrm{C}$ and $4{ }^{\circ} \mathrm{C}$ increase of the winter average temperature. Figure 1 shows the conceptual map with the main components of the model. The model includes regional climate change projections in order to simulate the future snow cover on the different ski resorts of Andorra. A snowmaking module simulates the effect of artificial snow production systems in the enhancement of the natural snow cover. The resulting snow cover at each ski resort will be the dynamic component of the environment upon the agents, in our model the ski visitors, will interact and take their decisions in basis of their internal state and the snow cover state.

The model was implemented using the NetLogo software version 5.0 (Wilensky, 1999) because it presents a good compromise between a user-friendly ABM programming environment and a powerful GIS extension for the study requirements. The following subsections describe the implementation of the main components of the model, that is, the environment and the agents.

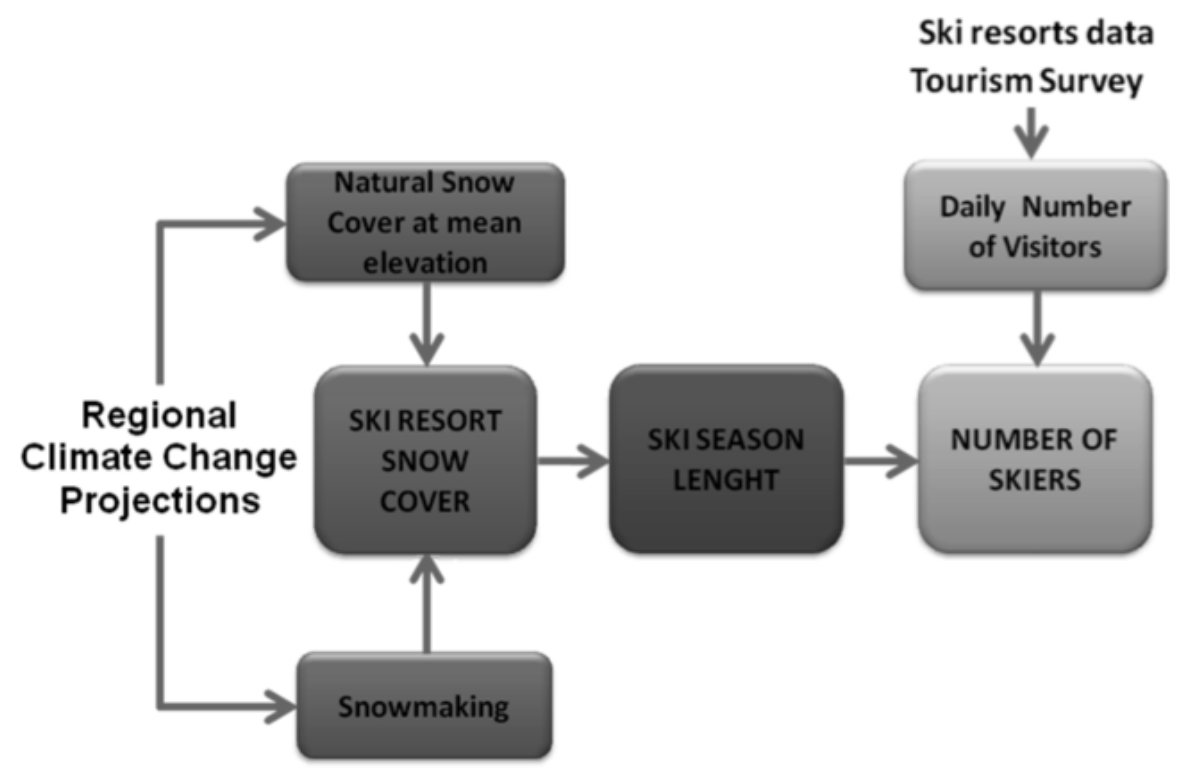

Figure 1: Conceptual map of the model

\subsection{Environment}

The environment, that is the space upon the agents interact and respond to its changes, is implemented using four Geographic Information System (GIS) layers: 
(1) the limits of the country, (2) the entrance points (customs) to Andorra, (3) the main roads connecting the entrance points and (4) the access and the surface area of the three ski resorts: GrandValira, Arcalís and Pal-Arinsal (figure 2). This latter layer changes over time in basis of the snow cover conditions and determines the season length according to the daily snowpack available in the resort. finst three layers remain static during the simulation.

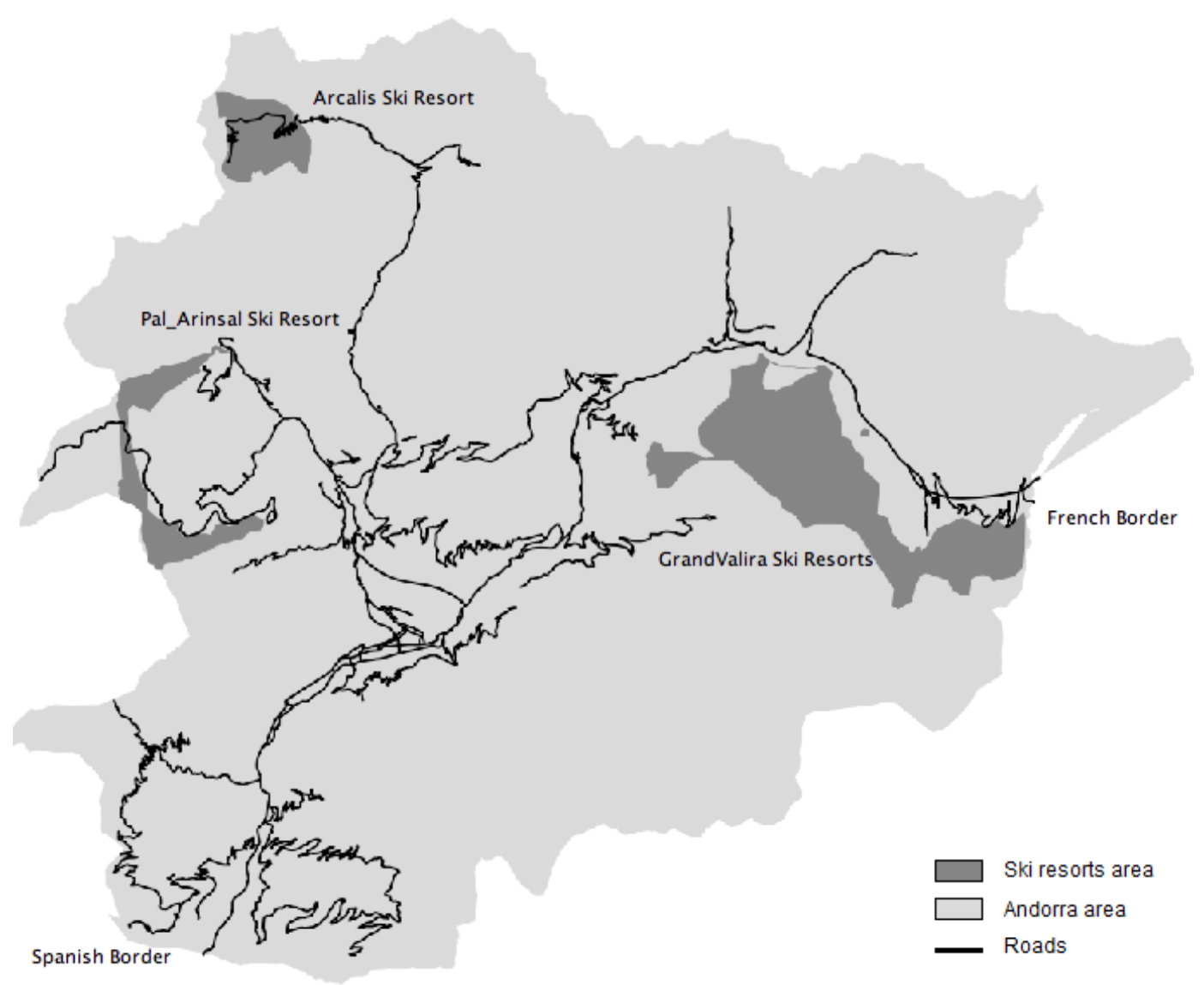

Figure 2: GIS layers used as dynamic environment for the ABM

\subsubsection{Natural Snow Cover and Season length}

The future natural snow cover at each ski resort is modeled using the projected changes in the Pyrenean daily snowpack during the 21st Century from LópezMoreno et al. (2009). This study simulates the snow depth and the snow duration running a Surface Energy Balance Model, the GRENBLS with climatic inputs provided by the HIRHAM Regional Climate Model. These projections are based on two future emissions scenarios: the SRES A2 and B2 scenarios (IPCC 2007) and for different altitudinal levels: 1500, 2000, 2500, and $3000 \mathrm{~m}$. This model performs a good agreement in the overall snow depth and duration between the observed and the simulated snowpack. The ski season length has been simulated using the snowpack projection in a reference elevation range for each ski resort and 
applying a $30 \mathrm{~cm}$ threshold. This threshold is one of the most used criterions to assess the climate change vulnerability of ski resorts, the 100-day rule (Abegg et al. 2007, Dawson \& Scott 2010, Scott et al. 2003, Scott \& McBoyle 2007, Steiger 2010). This refers to a standard denition for snow reliability assuming that 100 days per season with at least $30 \mathrm{~cm}$ of snow depth are required for a ski resort to be economically viable. Applying this criterion, the future season length has been estimated considering those days that the snow cover depth is at least $30 \mathrm{~cm}$. Figure 3 shows the mean control period (1960-1990) and future snow cover in PalArinsal (assuming a $2{ }^{\circ} \mathrm{C}$ and $4{ }^{\circ} \mathrm{C}$ increase of the winter average temperature) at 1800 and $2000 \mathrm{~m}$ of elevation. The grey area marks the $30 \mathrm{~cm}$ threshold showing those days that the snow cover is below the minimum conditions. Once the snow cover reaches this $30 \mathrm{~cm}$ value, it is assumed that the ski resort is open.

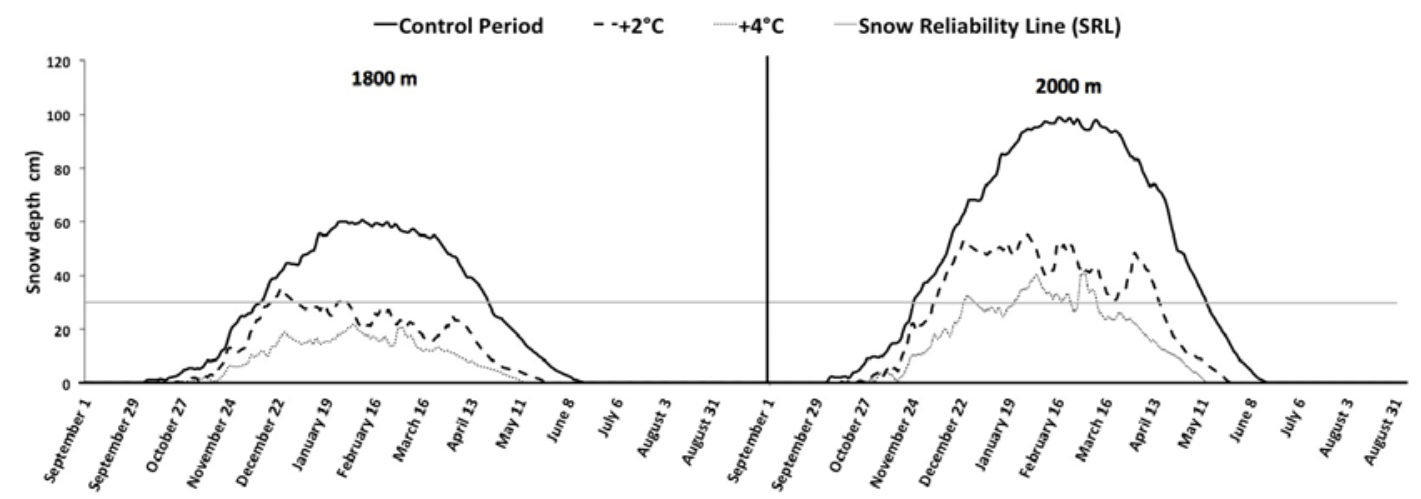

Figure 3: Mean control period (1960-1990) and future snow cover in Pal-Arinsal at 1800 and $2000 \mathrm{~m}$ and Snow Reliability Line (SRL) showing the $30 \mathrm{~cm}$ threshold to analyze the ski resorts viability.

The altitudinal distribution of each ski resort has been identified in order to assign an elevation range. As shown in figure 4, many ski resorts don't follow a linear altitudinal distribution and usually most of their ski area is concentrated in the highest half of the elevation range. Because of that, the reference values have been assigned selecting the lowest and the highest elevation between which most of the ski resort area (75\%) is concentrated. Thus, the altitudinal range assigned to Pal-Arinsal is 1900-2300, 2100-2400 for Arcalís and 2150-2450 for GrandValira. These ranges will make possible to analyze the extent of the potential impacts for each ski resort in relation to their elevation range. 


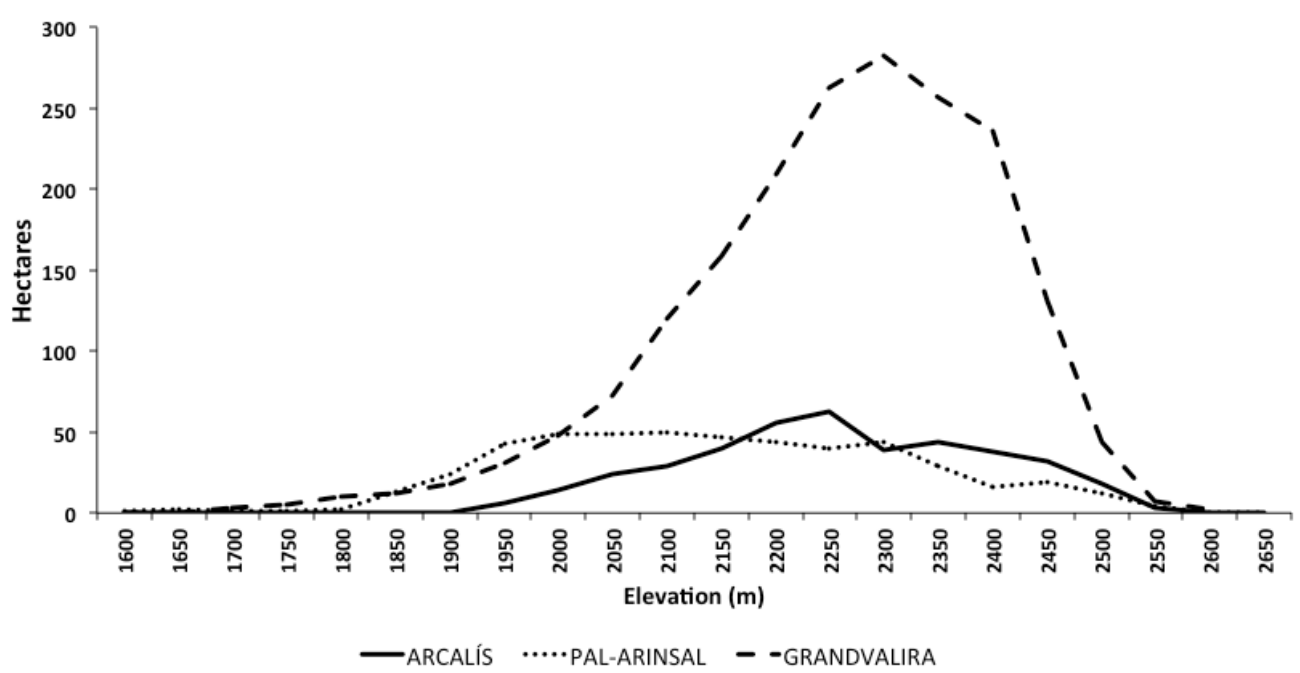

Figure 4: Altitudinal distribution of the Andorran ski resorts.

Once the altitudinal range has been defined, a daily snow cover is assigned for each elevation based on the projected snowpack from López-Moreno et al. (2009) study. Because the snow projections from this study are presented every $500 \mathrm{~m}$ (1500, 2000, 2500 and $3000 \mathrm{~m})$ a liner interpolation was needed between these elevations in order to achieve a finer resolution of the altitudinal variability.

\subsubsection{Snowmaking module}

Over the last few decades, ski resorts across the world have invested signficant amounts of money in artficial snow production systems (Steiger \& Mayer 2008). This adaptation strategy is intended to offset the variability of snowfall, guaranteeing good ski conditions, scheduled openings, and stable revenues. However, it is important to point out that these investments are not only motivated by climate variability. Snowmaking has also been used as a commercial and image strategy to extend the season and offer better snow conditions with the aim to increase revenues (Steiger \& Mayer 2008). With approximately 50\% of the Andorran ski area now covered by artficial snow production systems, the model includes a snowmaking module simulating the effect of these systems in the enhancement of the snow cover in order to achieve a more realistic projection of the ski season length. In this model, only the snowmaking to assure the minimum snow conditions has been simulated. The module simulates for each elevation that defines the altitudinal range of the ski resort that a maximum of $10 \mathrm{~cm}$ of snow are produced each day as long as the natural snow cover is below the $30 \mathrm{~cm}$ threshold (Scott et al. 2003, Steiger 2010). Only those days with a minimum temperature of $5^{\circ} \mathrm{C}$ are considered as potential snowmaking days (Steiger \& Mayer 2008). Thus, a new snowpack and resulting season length is achieved adding the effect of the snowmaking on the natural snow cover for each elevation. Figure 5 shows the enhancement of the natural snow cover at $1900 \mathrm{~m}$ in Pal-Arinsal following the 
defined parameters for a $+2^{\circ} \mathrm{C}$ climate change scenario.

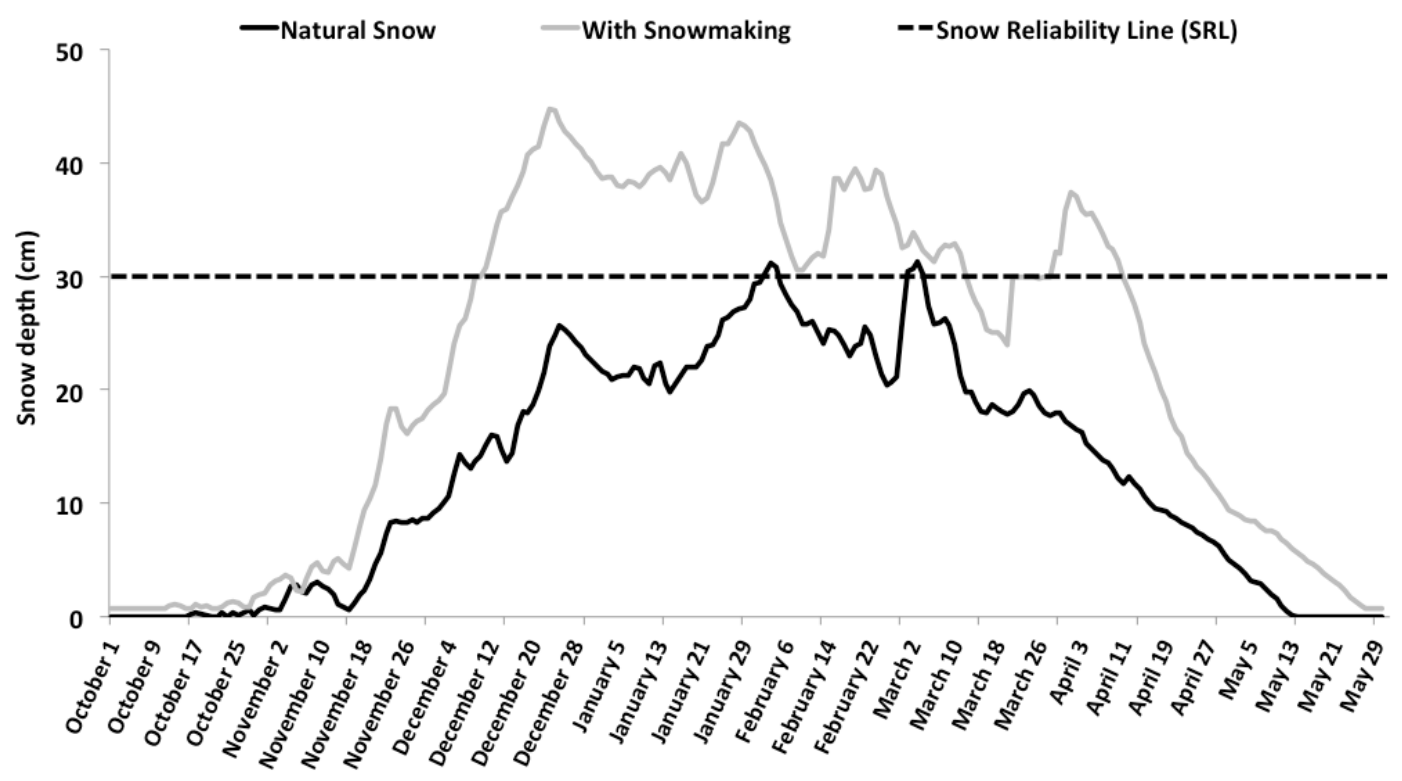

Figure 5: Enhancement with snowmaking of the natural snow cover at $1900 \mathrm{~m}$ in Pal-Arinsal assuming a $2^{\circ} \mathrm{C}$ increase of the winter average temperature.

\subsection{Entities and attributes}

Entities and attributes help to define an ABM (Grimm et al. 2006). An entity is a distinct or separate object or actor that behaves as a unit in the ABM and may interact with other entities or be affected by the environment. The current state of the object is characterized by attributes. An attribute is a variable that distinguishes an entity from other entities of the same type or category, or traces how the entity changes over time. In this model there are two main entities: the skiers, the agents of our model, and the ski resorts, which arfixed on the landscape. Skiers include the following attributes:

- Point of entry to Andorra.

- Visitor type (whether they are one-day visitors or overnight visitors).

- Mean daily expenditure.

- Destination ski resort.

- Current location (coordinates at each time step that locates the agent in the map).

All these attributes except the location are randomly assigned based on the real values and shares of these features obtained from the winter months data from the national tourism survey (Andorra Turisme, 2010). This survey represents a sample of 4010 international visitors and intends to capture the frequency, seasonality, 
nationality, activities and accommodation preferences of all kinf of Andorra visitors during winter, spring, summer and fall seasons. The location coordinates attribute is updated throughout the simulation according to where the skier is each time step. Ski resorts have the following attributes:

- Ski season length in days.

- State (whether it is open or closed).

- Location coordinates.

- Reference elevation.

The location coordinates and reference elevation are based on the geographical features of each ski resort. The ski season length and the status of the resorts will change throughout the simulation according to the projected snow cover at the reference elevation of the ski resort described above.

\subsubsection{Process overviewing and scheduling}

This section defines the actions of each entity, in what order are these actions executed, and when the different state variables are updated. Figure 6 shows the main flowchart of the model actions during a simulation. The model starts simulating the snow cover and setting the ski season starting day, ending day and length at each ski resort according to both the selected climate scenario (present, +2 ${ }^{\circ} \mathrm{C}$ or $+4{ }^{\circ} \mathrm{C}$ ) and if the snowmaking module is activated or not. Once these variables have been computed, the model can set the state of the different ski resorts as open or closed for each day of the simulation. After that, a dened number of daily agents are created based on the average values of tourist arrivals from the 2000-2010 national tourism surveys statistics in order to simulate the daily arrival of skiers. The value of the daily number of arrivals will be different each day representing seasonality due to peak and holiday periods such as Christmas and Easter. 


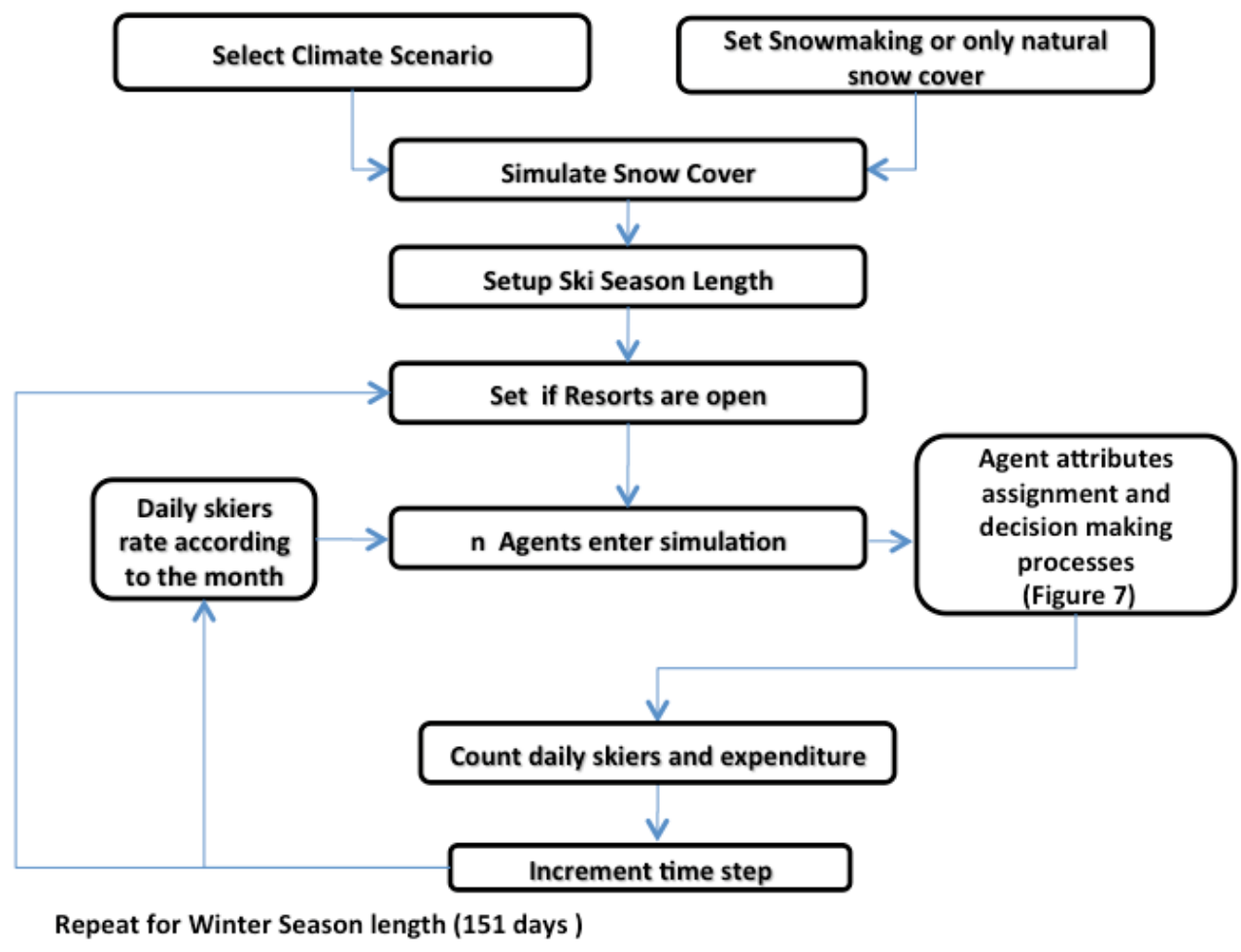

Figure 6: Model processes flowchart.

Once these agents (skiers) have been created, they each follow the sequence described in figure 7 to set the attributes value and perform the decision -making response in the model according to agent and landscape attributes. When the agent enters the simulation, it is assigned to a custom of entry and a visitor type based on the real statistical share of the feature. Using values drawn from the tourism surveys, the $73 \%$ of the agents will be randomly assigned as one-day visitors and the remaining as overnight visitors. If the assigned type is overnight visitor, the attribute length of stay is set to an average value of 3 days and a value of 1 if oneday visitor. In order to compute the daily and total expenditure of the skiers and simulating the difference of the mean expenditure in each type of visitor, the model assigns a value of 173 euros for overnight visitors and 110 euros for one-day visitors. In the same way, based on the attendance statistics, the agent is randomly assigned to one of the different ski resorts. As the type of visitors, all these parameters have been set with the statistical values obtained from the national tourism survey of Andorra (Andorra Turisme 2010). 


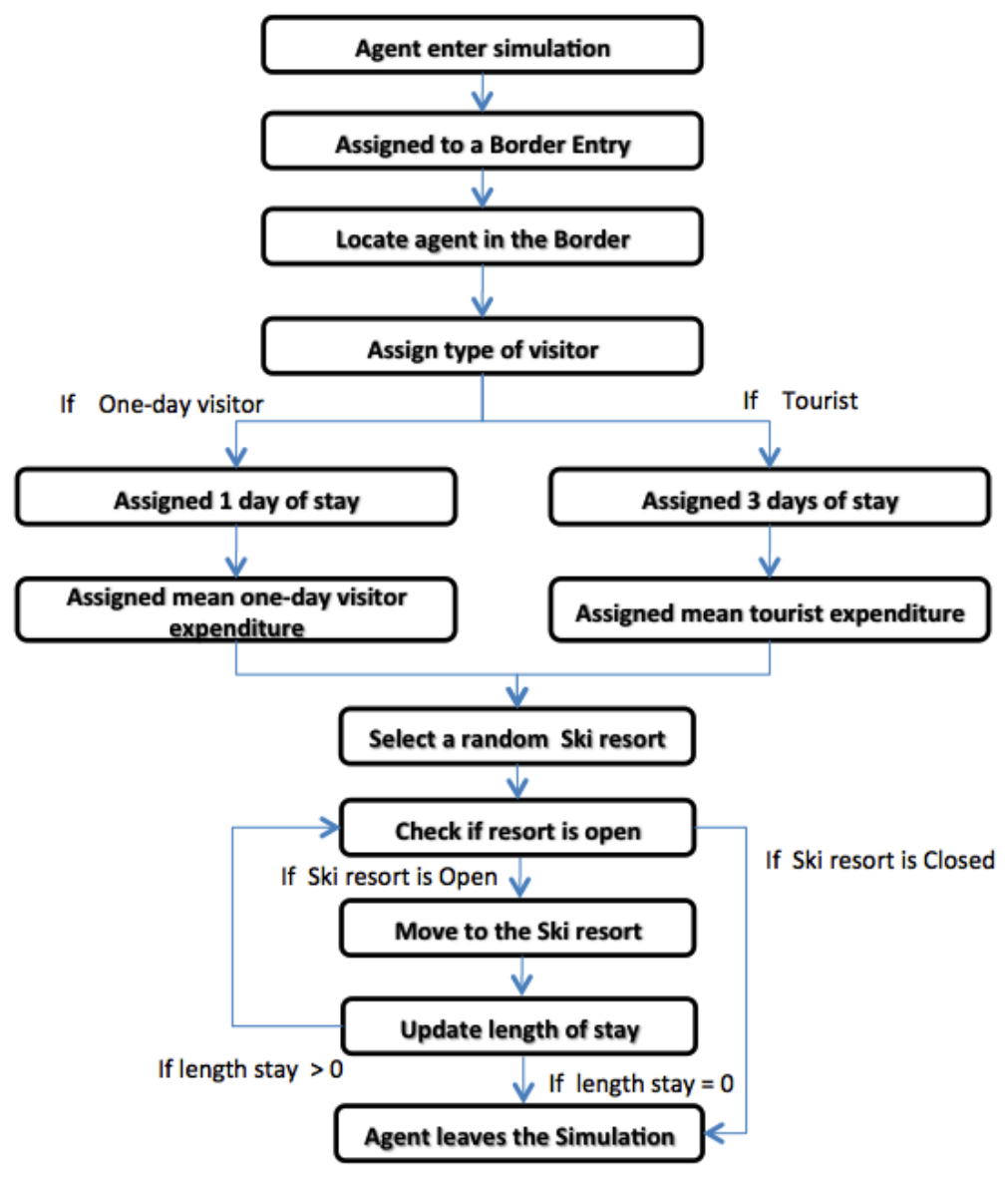

Figure 7: Agents decision-making and attribute assignment flowchart.

Once the model has created the daily number of agents and assigned a value to their attributes, the agent checks if the assigned ski resort is open or closed. If it is open, the agent moves to the ski resort. Otherwise, in this first version of the model, the agent leaves the country because there is no opportunity to ski in the selected ski resort. When all the agents have performed the decision making process the model computes the daily number of skiers at each ski resort and their total expenditure during the day. Finally the agents update their length of stay decreasing one day the value of this attribute. The agents with a new value of 0 , that is, those that were one-day visitors or in the last day of their stay leave the simulation. In order to simulate a standard winter season, each time step in the model represents 1 day and simulations run for 151 days, from December 1st to April 30th, an entire winter season in Andorra.

\section{Results}

Four different scenarios have been run in order to analyze the future impact of climate change-induced snow reductions on the Andorra ski industry. The two first scenarios assume an increase of the winter mean temperature (from November to April) of $+2{ }^{\circ} \mathrm{C}$ and $+4{ }^{\circ} \mathrm{C}$ respectively. The other two scenarios add the effect of 
the potential snowmaking on enhancing the natural snow cover and extending the season in the $+2{ }^{\circ} \mathrm{C}$ and $+4{ }^{\circ} \mathrm{C}$ base scenarios. The resulting number of skiers in the three ski resorts of Andorra (GrandValira, Arcalís and Pal-Arinsal) has been compared with the values of a reference period. The attendance of skiers in this reference-control period has been estimated as the average number of skier for each month from 2000 to 2010 as the reference value. Hence, the effect of a good or bad season in terms of skier attendance is diminished by the variability of the last ten years.

\subsection{Impact on ski season length}

In order to achieve a range of the potential impacts the average values for the control period have been compared with the projected future season length in the low and high reference elevations for each ski resort. Figure 9 shows the projected season for an average winter in Andorra at the different elevation ranges of the ski resorts. In the scenario assuming an increase of $2{ }^{\circ} \mathrm{C}$ only the lowest part of PalArinsal is significantly affected by a reduction in the season length (30\%), mainly at end of the season when snowfall is more erratic (Table 1). The higher parts of this resort and the other two resorts, with most of their ski area located at higher elevations (above $2100 \mathrm{~m}$ ), are not affected by this particular climate change scenario. Only the lowest area of Arcalís is affected by a minor reduction of a $3 \%$. Comparing this results with a scenario of $+2{ }^{\circ} \mathrm{C}$ including snowmaking it is noticed that the impact on the season length would be reduced a 5\% (25\%) in Pal-Arinsal and reduced to $0 \%$ in Arcalís. In the scenario assuming an increase of $4{ }^{\circ} \mathrm{C}$ all three ski resorts would suffer serious reductions in the lower areas. The Pal-Arinsal season would be almost entirely reduced (95\%) whereas GrandValira and Arcalís would suffer reductions of $17 \%$ and $27 \%$ respectively. The higher parts of the three ski resorts would remain reliable for almost the whole season. Only the highest area of Pal-Arinsal would be affected by a $3 \%$ reduction. Unlike the $+2{ }^{\circ} \mathrm{C}$, assuming and increase for $+4{ }^{\circ} \mathrm{C}$ snowmaking would not help significantly to alleviate these reductions. Because the worsening of climate conditions required to produce artificial snow, the capacity of snowmaking to extend the season at low elevations is highly reduced under a $+4{ }^{\circ} \mathrm{C}$ scenario. The potential days to efficiently produce snow at lower elevations, that indeed would be the areas requiring more snowmaking, would be significantly reduced. 


\begin{tabular}{lccccc}
\hline & \multicolumn{2}{c}{$+2^{\circ} \mathrm{C}$} & \multicolumn{2}{c}{$+4^{\circ} \mathrm{C}$} \\
\hline \multirow{2}{*}{ Ski Resort } & $\begin{array}{c}\text { Elevation } \\
(\mathrm{m})\end{array}$ & $\begin{array}{c}\text { Natural Snow } \\
\text { cover }\end{array}$ & $\begin{array}{c}\text { With } \\
\text { Snowmaking }\end{array}$ & $\begin{array}{c}\text { Natural } \\
\text { Snow cover }\end{array}$ & $\begin{array}{c}\text { With } \\
\text { Snowmaking }\end{array}$ \\
\hline Pal-Arinsal & 1900 & $-30 \%$ & $-25 \%$ & $-95 \%$ & $-95 \%$ \\
& 2300 & $0 \%$ & $0 \%$ & $-3 \%$ & $0 \%$ \\
\hline Arcalis & 2100 & $-3 \%$ & $0 \%$ & $-27 \%$ & $-25 \%$ \\
& 2400 & $0 \%$ & $0 \%$ & $0 \%$ & $0 \%$ \\
\hline GrandValira & 2150 & $0 \%$ & $0 \%$ & $-17 \%$ & $-14 \%$ \\
& 2450 & $0 \%$ & $0 \%$ & $0 \%$ & $0 \%$ \\
\hline
\end{tabular}

Table 1: Projected average change in the ski season length at the selected minimum and maximum elevation for each ski resort.

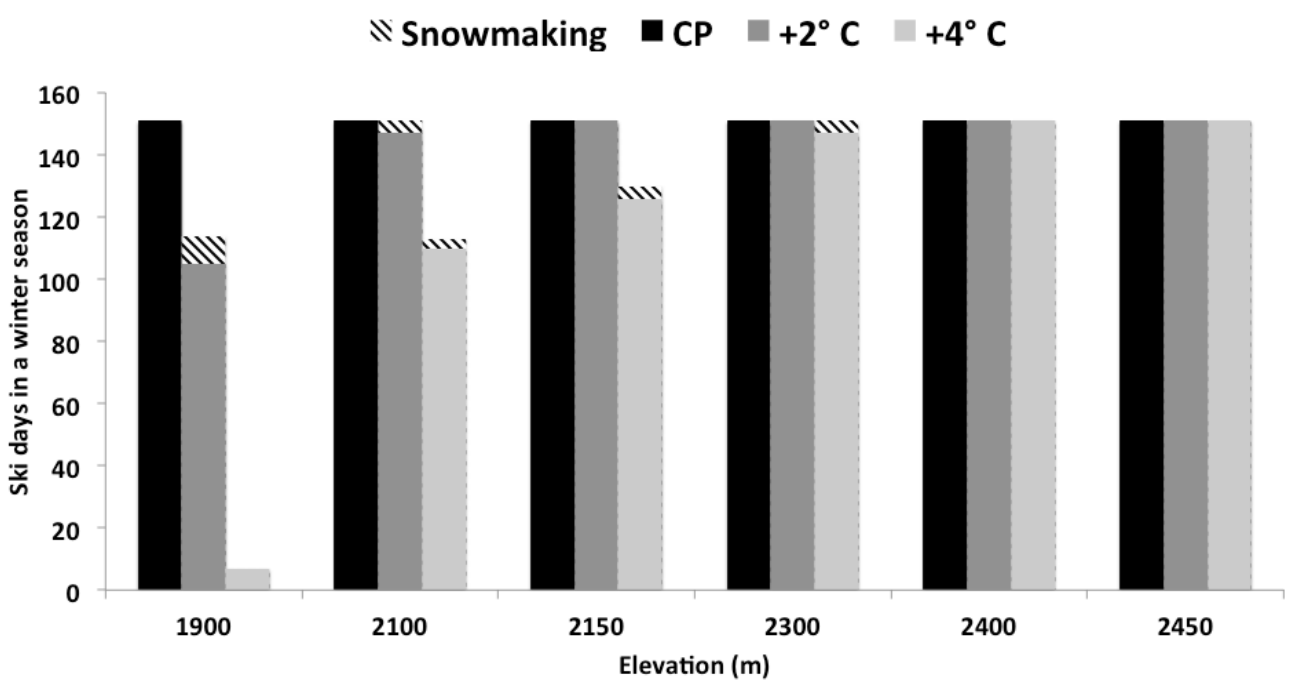

Figure 8: Ski days in an average winter season with natural snow cover and with snowmaking in the control period and assuming a $2{ }^{\circ} \mathrm{C}$ and $4{ }^{\circ} \mathrm{C}$ increase of the winter average temperature.

Applying the 100-day rule, the lowest parts of all three ski resorts would remain reliable with an increase of $+2{ }^{\circ} \mathrm{C}$. In contrast, with an increase of $+4{ }^{\circ} \mathrm{C}$, Pal-Arinsal would not be reliable even with snowmaking, whereas the other two resorts would remain reliable even the projected season reductions. None of the future climate projections would affect significantly the reliability at the highest elevations of all ski resorts located in Andorra.

\subsection{Impact on the number of skiers and their expenditure}

The use of an ABM model to simulate the interactions between the environment (snow cover) and the skiers makes it possible to connect the season length reductions at each ski resort with the drop of visitors at the regional scale in 
Andorra, and the related impact on expenditure in the country during a winter season. Table 2 shows the drop of the total number of skiers in Andorra under the different scenarios presented in the previous section. In order to analyze the potential range of the skiers reduction at a regional scale, a maximum and minim value has been estimated based on the extent of the impact at the two reference elevations of each ski resort. Thus, the maximum skiers reductions are estimated based on the projected impact on season length at low elevations and the minimum based on the impact at the high reference elevations. In a $+2{ }^{\circ} \mathrm{C}$ scenario, a small drop of the number of skiers and their expenditure is noticed because only the lowest area of Pal-Arinsal would be affected. On the other hand, the $+4{ }^{\circ} \mathrm{C}$ scenario indicates a more severe drop (15\% reduction in average) that would lead to a mean loss of skier-related revenue of approximately $50 \mathrm{M} €$ (value 2009) per season. In this case, the two ski resorts with higher visitor numbers (Pal-Arinsal and GrandValira) would be affected both at the beginning at the end of the season rising the extent of the impacts. Finally, it is noticed that in a $+4{ }^{\circ} \mathrm{C}$ scenario, when the drop of the skiers and their expenditure are remarkable, snowmaking doesn't have a significant impact on reducing the effects at a regional scale, only around a $2 \%$ of difference in the average drop of skiers regarding the $15,2 \%$ without snowmaking.

\begin{tabular}{lcccccc}
\hline & NATURAL SNOW COVER & \multicolumn{3}{c}{ SNOWMAKING } \\
\cline { 2 - 7 } Scenario & Max & Mean & Min & Max & Mean & Min \\
\hline$+2^{\circ} \mathrm{C}$ & $-4,4 \%$ & $-2,2 \%$ & $0,0 \%$ & $-3,2 \%$ & $-2 \%$ & $0 \%$ \\
$+4^{\circ} \mathrm{C}$ & $-30,2 \%$ & $-15,2 \%$ & $0,2 \%$ & $-26,2 \%$ & $-13 \%$ & $0 \%$ \\
\hline
\end{tabular}

Table 2: Projected changes in the total number of skiers.

\section{Discussion}

The objective of this study was to understand the climate change vulnerability of the Pyrenean winter tourism industry by means of a georeferenced ABM. The findings of the study are in line with previous literature analyzing the climate change impacts on the ski industry in other regions across the world. The reduction on the ski season length and the drop of the number of skiers has been projected especially on the lower elevations of the Andorra ski resorts. Snowpack in the south-oriented central and eastern areas of the Pyrenees will be the most strongly affected by climate change (López-Moreno et al. 2009) turning Andorra ski resorts into a potentially vulnerable area despite their high location (most of the ski area is above $2000 \mathrm{~m}$ ) in relation to other affected ski areas in Europe. On the other hand, snowmaking could help to extend and provide reliable season lengths with a midrange climate change scenario. However, due to the projected increase of the minimum and average temperature the worsening of the required conditions to efficiently produce snow will become a future constraint. Therefore, in line with previous studies, snowmaking cannot completely solve the problem of ensuring snow cover in Andorra at lower elevations and should be considered as a suitable short-term strategy, but not as a sustainable long-term adaptation strategy (Scott \& 
McBoyle 2007, Steiger 2010). In addition to being climatically marginal, snowmaking could entail future constraints in terms of security in water supplies, ecosystems alteration and infrastructure and energy costs associated with large increases in snowmaking volumes. Even if they are climatically viable, in the sense of ensuring the climatic conditions to efficiently produce snow, these factors can turn snowmaking into an uneconomic adaptation strategy to some ski operators and an unbearable measure for the ecosystem services of some other regions (Rixen et al. 2011, Scott \& McBoyle 2007, Steiger \& Mayer 2008).

Finally, as afirst initial model, it is pertinent to note that the projected result $\mathrm{s}$ should be taken as future general trends and not as accurate predictions for the Andorra ski resorts. This model will be adapted within a participatory planning process as a Planning Support tool involving and assisted by different stakeholders such as climate scientists, ski resorts managers and local planners and administrators. The tool will involve the different actors in a joint and transdisciplinary exercise to refine the model. Thus, it is expected the accuracy of the model outcome to be improved by discussing and rining the variables and parameters with the expertise of the stakeholders. Snow cover projections, the snowmaking module and the potential skier behavioral response are the main points to discuss and refine during this process. In this way, it is expected that not only the resulting model but also the discussion process could help the different stakeholders in understanding the vulnerability and the potential impacts as well as facilitate the decision-making process of designing and developing appropriate sustainable adaptation strategies to future climate change.

\section{Conclusion}

The georeferenced ABM methodology used in this study demonstrates potential as a tool to simulate the climate change impacts on the winter tourism and particularly to analyze the interaction between physical changes and socioeconomic implications. One of the most challenging issues in this kind of analysis is relating the projected physical impacts in ski areas to socioeconomic indicators, such as the shifts in skiers attendance or ski resorts revenues because a snow cover alteration (Dawson et al. 2009). One of the main reasons to use a georeferenced ABM was precisely to achieve a more detailed assessment of the socioeconomic dimension. The approach demonstrated here has potential to create and understand the linkage between the social and physical impacts relating the changes in the snowpack and resulting season length to the potential loss of skiers and their subsequent expenditure in the region. Moreover, compared to most of the models published to date, this methodology permits to include the behavioral response and the heterogeneity of the winter tourist profile, very important issues to take into account in this type of studies. First, because individuals can easily change their skiing behavior as a result of changing snow conditions in comparison to the expense and difficulty to implement structural and management adaptation strategies in the ski resorts supply side (Dawson et al. 2009). Secondly, in tourism modeling, visitors cannot be grouped as a single aggregated class with the same unique features. Tourists always perform different features and behavioral 
responses that should be included in the analysis to capture a more realistic understanding of the macro-level phenomena such are the impacts on a regional scale.

Future areas of rinement must focus on improving the heterogeneity of the agents (skiers) by including ski level or activity involvement and different behavioral response to environmental changes in basis of their profile. On the other hand, the use of a georeferenced landscape made possible to capture the intrinsic spatial features of tourism phenomena. In our case, the ski resorts location and elevation has been taken into account with this approach. In this way, future developments must take into account the finence of other geographical parameters such as travel distances or spiecties of the tourism destinations landscape such as slope orientation.

Finally, we are working to extend the model to other ski resorts in French and Spanish parts of the Pyrenees. This will allow the analysis of impacts at a regional scale, including the activity and spatial substitution of the skiers as well as other behavioral responses identified in previous studies e.g. Behringer et al. 2000, Dawson et al. 2011, Fukushima et al. 2003, Pütz et al. 2011, Shih et al. 2009, Unbehaun et al. 2008.

Acknowledgements. The authors are thankful to Dr. Ignacio López-Moreno for share and support in climate projections data and to the Working Community of the Pyrenees (CTP) forfina ncial support of this study. First author acknowledges also a predoctoral grant from Government of Andorra and Crèdit Andorrà Foundation, BTC2010/2011-0006-AND.

\section{LITERATURE CITED}

Abegg B, Agrawala S, Crick F, de Montfalcon A (2007) Climate change impacts and adaptation in winter tourism. In: Climate change in the European Alps: adapting winter tourism and natural hazards management. Paris: Organization for Economic Co-operation and Development

Andorra Turisme (2010) National Survey. Andorra Government

Axtell RL, Epstein JM, Dean JS, Gumerman GJ, Swedlund AC, Harburger J, Chakravarty S, Hammond R, Parker J, Parker M (2002) Population Growth and Collapse in a Multi-Agent Model of the Kayenta Anasazi in Long House Valley. Proc Natl Acad Sci USA 99(3):7275-7279

Beniston M (2003) Climatic change in mountain regions: A review of possible impacts. Climatic Change 59:5-31

Behringer J, Bürki R, Fuhrer J (2000) Participatory integrated assessment of adaptation to climate change in alpine tourism and mountain agriculture. Integrated Assessment 1(3).331-338 
Berger T, Schreinemachers P (2006) Creating agents and landscapes for multiagent systems from random samples. Ecology and Society 11(2):19

Bicknell S, McManus P (2006) The canary in the coalmine: Australian ski resorts and their response to climate change. Geographical Research 44:386-400

Bithell M, Brasington J (2009) Coupling agent-based models of subsistence farming with individual-based forest models and dynamic models of water distribution. Environ Modell Softw 24 (2):173-190

Bousquet F, Le Page C (2004) Multi-agent simulations and ecosystem management: A review. Ecol Model 76(3-4):313-332

Breiling M, Charamza P (1999) The impact of global warming on winter tourism and skiing: a regionalized model for Austrian snow conditions. Regional Environmental Change 1(1):4-14

CADS (2010) 2n Informe sobre el canvi climàtic a Catalunya. Consell Assessor per al Desenvolupament Sostenible. Generalitat de Catalunya

Crooks AT (2010) Constructing and Implementing an Agent-Based Model of Residential Segregation through Vector GIS. Int J Geogr Inf Sci 24(5): 661-675

Dawson J, Scott D, McBoyle G (2009) Analogue analysis of climate change vulnerability in the US Northeast ski tourism. Climate Res 39(1):19

Dawson J, Scott D (2010) Systems analysis of climate change vulnerability for the US Northeast ski sector. Tourism Planning and Development 7(3):219-235

Dawson J, Havitz M, Scott D (2011) Behavioral Adaptation of Alpine Skiers to Climate Change: Examining Activity Involvement and Place Loyalty. Journal of Travel and Tourism Marketing, 28(4):388-404

Deadman PJ, Robinson DT, Moran E, Brondizio E (2004) EFFects of Colonist Household Structure on Land Use Change in the Amazon Rainforest: An Agent Based Simulation Approach. Environment and Planning B: Planning and Design 31(5):693-709

Elsasser, H, Bürki R (2002) Climate change as a threat to tourism in the Alps. Climate Res 20:253-257

Feuillette S, Bousquet F, Le Goulven P (2003) Sinuse: A multi-agent model to negotiate water demand management on a free access water table. Environ Modell Softw 18(5):413-427

Fukushima T, Kureha M, Ozaki N, Fujimori Y, Harasawa H (2003) Influences of 
air temperature change on leisure industries: case study on ski activities. Mitigation and Strategies for Climate Change 7:173-189

Galloway R (1988) The potential impact of climate change on Australian ski fields. In: Pearman G (ed) Greenhouse: planning for climatic change. CSIRO, Melbourne

Gimblett R, Skov-Petersen H (2008) Monitoring, Simulation, and Management of Visitor Landscapes. University of Arizona, Tuscon.

Grimm V, Berger U, Bastiansen F, Eliassen S, Ginot V, Giske J, Goss-Custard J, Grand T, Heinz SK, Huse G (2006) A standard protocol for describing individualbased and agent-based models. Ecol Model 198(1-2):115-126

Heo I, Lee S (2008) The Impact of Climate Changes on Ski Industries in South Korea In the case of the Yongpyong Ski resort. Journal of the Korean geographical society. 43(5):715-727

Intergovernmental Panel on Climate Change IPCC (2007) Climate change 2007: synthesis report. Summary for policy makers. Fourth Assessment Report. United Nations Intergovernmental Panel on Climate Change, Geneva

Itami R (2002) Mobile agents with spatial intelligence. In Integrating geographic information systems and agent-based modeling techniques for simulating social and ecological processes, ed. H. R. Gimblett, 191-210. Oxford: Oxford University Press.

Janssen MA (2009) Understanding artificial Anasazi. Journal of Artificial Societies and Social Simulation 12

Johnson PA, Sieber RE (2009) Agent-based modelling: A dynamic scenario planning approach to tourism PSS. In S. Geertman, J., Stillwell (Eds.), Planning Support Systems: Best Practices and New Methods (pp. 211-226). Berlin: Springer

Johnson PA, Sieber RE (2010) An Individual-Based Approach to Modeling Tourism Dynamics. Tourism Analysis 15(5):517-530

Johnson PA, Sieber RE (2011) An Agent-Based Approach to Providing Tourism Planning Support. Environment and Planning B: Planning and Design 38(3):486504

Kohler TA, Gumerman GJ (1999) Dynamics in human and primate societies: Agent-based modeling of social and spatial processes. New York: Oxford University Press.

König U, Abegg B (1997) Impacts of climate change on tourism in the Swiss Alps. 
Journal of Sustainable Tourism 5(1):46-58

Ligmann-Zielinska A, Jankowski P (2007) Agent-based models as laboratories for spatially explicit planning policies. Environment and Planning B 34:316-335

López-Moreno JL, Goyette S, Beniston M (2009) Impact of climate change on snowpack in the Pyrenees: horizontal spatial variability and vertical gradients. J Hydrol 374:384-396

Moen J, Fredman P (2007) Effects of Climate Change on Alpine Skiing in Sweden. Journal of Sustainable Tourism 15(4):418-437

Parker DC, Manson S, Janssen MA, Hoffmann MJ, Deadman P (2003) Multi-agent systems for the simulation of land-use and land-cover change: a review. Ann Assoc Am Geogr 93(2):314-337

Parrott L, Chion C, Martins CCA, Lamontagne P, Turgeon S, Landry JA, Zhens B, Marceau DJ, Michaud R, Cantin G, Ménard N, Dionne S (2011). A decision support system to assist the sustainable management of navigation activities in the St. Lawrence River Estuary, Canada. Environ Modell Softwa 1-16. DOI: 10.1016/j.envsoft.2011.08.009.

Perez L, Dragicevic S (2010) Modeling mountain pine beetle infestation with an agent-based approach at two spatial scales. Environ Modell Softw 25(2):223-236

Pütz M, Gallati D, Kytzia S, Elsasser H, Lardelli C, Teich M, WAltert F, Rixen C (2011) Winter Tourism, Climate Change, and Snowmaking in the Swiss Alps: Tourists’ Attitudes and Regional Economic Impacts. Mt Res Dev 28:292-298

Rixen C, Teich M, Lardelli C, Gallati D, Pohl M, Pütz M, Bebi P (2011) Winter Tourism and Climate Change in the Alps: An Assessment of Resource Consumption, Snow Reliability, and Future Snowmaking Potential. Mt Res Dev 31(3):229-236

Scott D, McBoyle G, Mills B (2003) Climate change and the skiing industry in southern Ontario (Canada): Exploring the importance of snowmaking as a technical adaptation. Climate Res 23:171-181

Scott, D, McBoyle, G., Mills, B., Minogue, A (2006) Climate change and sustainability of ski-based tourismin eastern North America: A reassessment. Journal of Sustainable Tourism 14(4):376-398

Scott D, McBoyle G (2007) Climate change adaptation in the ski industry. Mitigation and Adaptation Strategies to Global Change 12(8):1411-1431

Scott D, McBoyle G, Minogue A (2007) The implications of climate change for the 
Qubec ski industry. Global Environmental Change 1:181-190

Scott D, Dawson J, Jones B (2008) Climate change vulnerability of the US Northeast winter recreationTourism sector. Mitigation Adaptation Strategies for Global Change 13:577-596

Shih C, Nicholls S, Holecek DF (2009) Impact of weather on downhill ski lift ticket sales. Journal of Travel Research 47(3):359-372

Smajgl A, Brown DG, Valbuena D, Huigen MGA (2011) Empirical characterisation agent behaviours in socio-ecological systems. Environ Modell Softw 26:837-844

Steiger R, Mayer M (2008) Snowmaking and climate change. Future options for snow production in Tyrolean ski resorts. Mt Res Dev 28:292-298

Steiger R (2010) The impact of climate change on ski season length and snowmaking requirements in Tyrol, Austria. Climate Res 43(3):251-262

Töglhofer C, Eigner F, Prettenthaler F (2011) Impacts of snow conditions on tourism demand in Austrian ski areas. Clim Res 46:1-14

Uhlmann B, Goyette S, Beniston M (2009) Sensitivity analysis of snow patterns in Swiss ski resorts to shifts in temperature, precipitation and humidity under condition of climate change. Int J Climatol 29:1048-1055

Unbehaun W, Probstl U, Haider W (2008) Trends in winter sports tourism: Challenges for the future. Tourism Review 63(1):36-47

Wilensky U (1999) NetLogo (and NetLogo User Manual), Center for Connected Learning and Computer-Based Modeling, Northwestern University. Available at http://ccl.northwestern.edu/netlogo/

Yang J, Wan C (2010) Progress in Research on the Impacts of Global Climate Change on Winter Ski Tourism. Advances in climate change research 1(2):55-62 